\title{
Corrigendum: Analysis of Perceptual Expertise in Radiology - Current Knowledge and a New Perspective
}

\author{
Stephen Waite ${ }^{1 *}$, Arkadij Grigorian ${ }^{1}$, Robert G. Alexander ${ }^{2,3,4}$, Stephen L. Macknik ${ }^{2,3,4}$, \\ Marisa Carrasco ${ }^{5}$, David J. Heeger ${ }^{5}$ and Susana Martinez-Conde ${ }^{2,3,4 t}$ \\ ${ }^{1}$ Department of Radiology, SUNY Downstate Medical Center, Brooklyn, NY, United States, ${ }^{2}$ Department of Ophthalmology, \\ SUNY Downstate Medical Center, Brooklyn, NY, United States, ${ }^{3}$ Department of Neurology, SUNY Downstate Medical Center, \\ Brooklyn, NY, United States, ${ }^{4}$ Department of Physiology/Pharmacology, SUNY Downstate Medical Center, Brooklyn, NY, \\ United States, ${ }^{5}$ Department of Psychology and Center for Neural Science, New York University, New York, NY, United States
}

Keywords: visual perception, expertise, radiology, visual search, perceptual learning, attention, holistic processing, gist

\section{A Corrigendum on}

Analysis of Perceptual Expertise in Radiology - Current Knowledge and a New Perspective by Waite, S., Grigorian, A., Alexander, R. G., Macknik, S. L., Carrasco, M., Heeger, D. J., et al. (2019) Front. Hum. Neurosci. 13:213. doi: 10.3389/fnhum.2019.00213

In the original article, there was a mistake in the caption for Figure 5. The caption incorrectly states that the figure was from Reed et al. (2011) however the figure was reprinted from Litchfield and Donovan (2016) with permission. The correct legend appears below.

The authors apologize for this error and state that this does not change the scientific conclusions of the article in any way. The original article has been updated.

Figure 5. Reprinted from Litchfield and Donovan (2016) with permission. Two different experience groups-expert radiologists and psychology students-searched for lung nodules from CXR images using the flash-preview moving window (FPMW) paradigm. Participants looked at the target word for $15 \mathrm{~s}$ ("lung nodule"). They then saw a fixation cross for $200 \mathrm{~ms}$, then either a mask preview (random array of colored pixels) or a CXR (a 'scene' preview) for $250 \mathrm{~ms}$. Next, participants saw a mask for $50 \mathrm{~ms}$ and then a second fixation cross for $400 \mathrm{~ms}$. Following a second presentation of the fixation cross, they conducted a windowed search, with a 2.5-degree radius window restricting the field of view (Litchfield and Donovan, 2016).

Received: 02 July 2019

Accepted: 23 July 2019

Published: 13 August 2019

Citation:

Waite S, Grigorian A, Alexander RG, Macknik SL, Carrasco M, Heeger DJ and Martinez-Conde S (2019)

Corrigendum: Analysis of Perceptual Expertise in Radiology - Current Knowledge and a New Perspective. Front. Hum. Neurosci. 13:272. doi: 10.3389/fnhum.2019.00272

\section{REFERENCES}

Litchfield, D., and Donovan, T. (2016). Worth a quick look? Initial scene previews can guide eye movements as a function of domain-specific expertise but can also have unforeseen costs. J. Exp. Psychol. Hum. Percept. Perform. 42, 982-994. doi: $10.1037 / x h p 0000202$

Reed, W. M., Ryan, J. T., McEntee, M. F., Evanoff, M. G., and Brennan, P. C. (2011). The effect of abnormality-prevalence expectation on expert observer performance and visual search. Radiology 258, 938-943. doi: 10.1148/radiol.10101090

Copyright () 2019 Waite, Grigorian, Alexander, Macknik, Carrasco, Heeger and Martinez-Conde. This is an open-access article distributed under the terms of the Creative Commons Attribution License (CC BY). The use, distribution or reproduction in other forums is permitted, provided the original author(s) and the copyright owner(s) are credited and that the original publication in this journal is cited, in accordance with accepted academic practice. No use, distribution or reproduction is permitted which does not comply with these terms. 